\title{
Use of nanoadvanced activated carbon, alumina and ferric adsorbents for humics removal from water: isotherm study
}

\author{
Cecile Andre Stanford ${ }^{1} \cdot$ Majeda Khraisheh ${ }^{2} \cdot$ Fares Al Momani $^{2} \cdot$ Ahmad B. Albadarin $^{3} \cdot$ Gavin M. Walker $^{3}$. \\ Mohammad A. Al Ghouti ${ }^{4}$
}

Received: 8 December 2019 / Accepted: 3 March 2020 / Published online: 17 March 2020

(C) The Author(s) 2020

\begin{abstract}
The adsorption of humic substances on three different adsorbents was investigated and adsorption isotherms were applied in this research. The three adsorbents studied include granular activated carbon (GAC), ferric oxihydroxide in its beta form ( $\beta$ - $\mathrm{FeOOH})$ and iron-coated activated alumina (AAFS). Physical and chemical characteristics of the adsorbents were also fully investigated. Calcium was added to the HS solution in order to represent water with a hardness equivalent to water hardness typically found in London (UK). The examination of the GAC indicated a large microporous area with lower surface area associated with meso- and macropores. The AAFS and $\beta-\mathrm{FeOOH}$ did not present any microporous area. The overall surface area was high for GAC $\left(980 \mathrm{~m}^{2} \mathrm{~g}^{-1}\right)$ but lower for AAFS $\left(286 \mathrm{~m}^{2} \mathrm{~g}^{-1}\right)$ and $\beta$-FeOOH $\left(360 \mathrm{~m}^{2} \mathrm{~g}^{-1}\right)$. The Freundlich isotherm model was fitted to all adsorbent-adsorbate systems. It was shown that GAC offered a large adsorption capacity for removal of low molecular weight humics F1 (MW 0-5 kDa) but not for substances with molecular weight larger than $10 \mathrm{kDa}(\mathrm{F} 3)$. The $\beta$-FeOOH adsorption capacity was only $0.43 \mathrm{mg} \mathrm{g}^{-1}$, compared with 9.11 and $2.55 \mathrm{mg} \mathrm{g}^{-1}$ on GAC and AAFS, respectively. On the contrary, F1 is not well adsorbed and only F2 (5-10 kDa) can be efficiently removed by AAFS and $\beta-\mathrm{FeOOH}$. It was strongly suggested that precipitation/condensation occurred on the adsorbent surface.
\end{abstract}

Keywords Humic acids $\cdot$ Drinking water $\cdot$ Adsorption $\cdot$ Activated alumina $\cdot$ Ferric oxides

\section{Introduction}

In natural waters, humic substances (HS) are normally present as natural organic constituents of aquatic plants and animals [1-8]. HS are the result of microbiological and chemical oxidation, which decompose carbohydrates of vegetal and animal cells into small units. Therefore, HS are expected to be a mixture of aliphatic and aromatic units with functional groups including carboxylic, ester, alcohol,

Majeda Khraisheh

m.khraisheh@qu.edu.qa

Southern Water, Southern House, Brighton, UK

2 Department of Chemical Engineering, Qatar University, Doha, State of Qatar

3 Department of Chemical Sciences, Bernal Institute, University of Limerick, Limerick, Ireland

4 Department of Biological and Environment Sciences, Qatar University, 2713, Doha, State of Qatar ether, ketone, phenol, amine, amide, pyridine, and pyrrole [9]. In water supply, the presence of HS may cause certain health effects and affect the aesthetics sense of consumers and reduces the water treatment efficiency $[10,11]$. It can also have a detrimental effect on fertility of soil, causes water acidity, influence pollutants' transport and mitigation and reduces the efficiency of chemical disinfection. Therefore, it is important to characterize the HS present in water to ensure suitable drinking water treatment and improvement of water quality [12-15]. HS may comprise of various components with different molecular weights. The heterogeneity of HS causes them to have broader distribution of adsorption affinities. It was demonstrated that HS with higher molecular weights and hydrophobic nature possess greater potential for adsorption on mineral adsorbents $[12,16]$. On the other hand, enhanced iron oxide mineral-containing carboxylic functions groups were used [17] to adsorb fulvic acid components, pattern of fractionation which is in consistence with surface complexation processes. An example of such surface complexation processes could be ligand exchange [17].

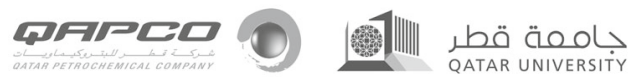


Coagulation/filtration, membrane filtration, adsorption, oxidation and ion exchange are different processes used in order to remove humic acids [3, 4, 18-21]. Among all the physicochemical processes occurring in the environment that are responsible for the uptake of organic and inorganic substances, the most important process is adsorption [22, 23]. The extent of adsorption depends upon several factors such as $\mathrm{pH}$, ionic strength, pollutant's nature and concentration [24]. Furthermore, simultaneous occurrence of complex substances and competing ions may also affect the extent of adsorption. Investigation of adsorption isotherms has been carried out for HS as adsorbate and various adsorbents such as iron-coated activated alumina, granular activated carbon and ferric oxihydroxide in its beta form in wastewater treatment helped to provide important information about the pathways of reaction, adsorption mechanisms and behaviour [25, 26]. The adsorption capacity of pollutant removal from aqueous solutions is important to design the adsorption treatment plants [27-29]. Equilibrium (with or without reversibility) represents a thermodynamically stable adsorbent-adsorbate system with a minimum energy level $[30,31]$. Given that the humic substances are includes a wide variety of non-biodegradable organic matter, such as, carboxylic and phenolic groups, they cover a large molecular weight range. Accordingly, finding a unique removal mechanism is hard. Hence, the understanding of the numerous physicochemical properties and the surface mechanism such as adsorption are helpful.

New adsorbents of interest for HS removal tend to contain iron or aluminium. This idea comes from the efficiency of coagulation in removing HS (heavy MW range), hence, the interest of applying the destabilisation and complex forming capacities to adsorbents. From these considerations, two adsorbents were tested for these new applications. They were activated alumina coated and iron oxihydroxide $\beta-\mathrm{FeOOH}$ (known as akaganeite). In addition, all studies involved in humics removal are dealing the material without consideration of the impact of the molecular weights on the adsorption process. Here, the different fractions are studied to better understand the effect of the wide molecular weight range on the removal process. In addition, the following physical and chemical characteristic will also be investigated: bulk density, porosity, surface area and the pore size distribution. The current research deals with the investigation and reporting of available micropores and mesopores on the adsorption profile of HS onto the adsorbents for the removal and/or concentration minimization of HSs from synthetic water and wastewater samples. Three adsorption models are considered including Langmuir, Henry and Freundlich. Furthermore, the effect of different parameters such as $\mathrm{pH}$ and initial concentration of solution on adsorption capacity are considered. Scanning electron microscopy (SEM) and Fourier transform infrared spectroscopy (FTIR) are employed to investigate the adsorption mechanism and to collect qualitative information about the solute adsorption. Adsorbents are neutral compounds although their surfaces are electrically charged according to the surface functional groups and to the $\mathrm{pH}$ of the water they are in contact with. The adsorbents need to present a favourable surface area with a wide pore size distribution such as the wide range of MW is able to penetrate the porous structure. A good adsorbent should also present a favourable zero point of charge and a variety of functional groups able to ionize $[32,33]$. Hence, the zero point of charge $\left(\mathrm{pH}_{\mathrm{zpc}}\right)$ that gives the surface charge according to the $\mathrm{pH}$, is an essential piece of information in order to understand and explain the adsorption process.

\section{Materials and methods}

\subsection{The adsorbent and the adsorbate}

Three different types of adsorbents were used in this study: granular activated carbon (GAC) obtained from Universal Mineral Supplies Ltd., beta form of ferric oxihydroxide akaganeite $(\beta-\mathrm{FeOOH})$; acquired from Wasserchemie, and iron-coated activated alumina (AAFS 50) purchased from Alcan Chemicals GEH. Initially, the adsorbents were cleaned from dirt and inherent pulp by washing using distilled water. They were subsequently dried at $105^{\circ} \mathrm{C}$ for $3 \mathrm{~h}$. After drying, the adsorbents were crushed to a powder form with dark brown colour and with different size distribution (sieves and shaker from Endecotts). Four diameters were measured: $d_{10}$ (effective diameter), $\mathrm{d}_{50}$ (median diameter), $\mathrm{d}_{60}$ and $\mathrm{d}_{90}$. They correspond to respectively $10 \%, 50 \%, 60 \%$ and $90 \%$ of the adsorbent grains in weight.

Humic acid used as adsorbate was acquired from Aldrich, $\mathrm{UK}$, in a form of powder with wide molecular mass range. Humics have a molecular weight ranging from 20,000 to $50,000 \mathrm{Da}$ [34]. Separation into various ranges of molecular weight is termed fractionation. This is carried out in order to investigate the behaviour of each MW range towards adsorption. Each fraction may be regarded as a component during adsorption enabling a multicomponent adsorption model to be applied [35-37]. For fractionation of humic substances and to prepare solutions with specific molecular mass of humic acid, ultrafiltration membranes (Vivaflow 50 obtained from Sartorius Ltd., UK) were used. The membrane material consists of polyethersulfone (PES).

Such a fractionation system has been used previously by Khraisheh [34]. Three different solutions, i.e. F1, F12 and F123 with variable molecular mass of $\mathrm{HS}$ as $<5 \mathrm{kDa},<$ $10 \mathrm{kDa}$ and $<50 \mathrm{kDa}$ respectively were prepared. The samples were stored at $4{ }^{\circ} \mathrm{C}$. To obtain dissolved organic content of $10 \mathrm{mg} / \mathrm{L}$, each solution was diluted with deionized water accordingly. The $\mathrm{pH}$ of the solutions was maintained at 7 . 


\subsection{Characterization of adsorbents}

To compare qualitatively the organic functional groups of humic substances adsorbed on the adsorbents, a Fourier transform infrared analysis was carried out. Samples were taken from the column after adsorption of various fractions of MW of HS onto the selected adsorbents. It was carried out as given in $[38,39]$, on the FTIR Perkin Elmer Spectrophotometer RX I instrument. The samples (dry adsorbent with and without adsorbed humic matter) were dried for $18 \mathrm{~h}$ at $65^{\circ} \mathrm{C}$. The disc, which was formed, was placed in the instrument. The disc was scanned in transmission mode through a wavelength range from 400 to $4000 \mathrm{~cm}^{-1}$. Before each measurement, the instrument was run to collect the background spectrum which was then automatically subtracted from the sample spectrum.

Scanning electron microscopy (SEM) (Cambridge 90B SEM (Leo, UK) apparatus-Eastman Dental Institute, University College London) was also used for samples morphology analysis.

\subsection{Surface area, pore size analysis and porosity}

Using BET method, the adsorbents surface area was obtained by assuming the section area of nitrogen molecular as $0.162 \mathrm{~nm}^{2}$. Using nitrogen adsorption apparatus (Surface Area Analyser/Micrometrics Instrument Corp., model ASAP 2010), the nitrogen adsorption isotherms were obtained at $77 \mathrm{~K}$ nitrogen adsorption isotherms of the adsorbents were determined at $77 \mathrm{~K}$. Before nitrogen adsorption, the sample $(0.4 \mathrm{~g})$ was outgassed under vacuum for period of $24 \mathrm{~h}$ at temperature of $100{ }^{\circ} \mathrm{C}$. Porosity and grain density were also determined (Eq.1 and 2). The adsorbents were soaked and mixed with water overnight, to fill the pores with water. It was then dried at approximately $50{ }^{\circ} \mathrm{C}$.

Porosity $=\varepsilon_{p}=\frac{V_{1}-\left(V_{4}-V_{3}\right)}{V_{1}}$

Graindensity $=\frac{\text { Bulkdensity }}{1-\text { poured porosity }}$

where $V_{1}$ is the unpacked volume, $V_{2}$ is the packed volume, $V_{3}(25 \mathrm{~mL})$ is the volume of water added and $V_{4}$ is the final volume after elimination of air ( $V_{2}$ is used instead of $V_{1}$ to obtain the packed porosity).

\section{$2.4 \mathrm{pH}$ of zero point charge}

The surface charge of the adsorbents was estimated by following an alkalimetric titration method [38]. $24 \times 100 \mathrm{~mL}$ Erlenmeyer flasks were used, containing $2.5 \mathrm{~g}$ of the adsorbent, a known amount of acid $\mathrm{HCl}(0.25 \mathrm{M})$ or base $\mathrm{NaOH}$ $(0.25 \mathrm{M})$, from 0 to $6 \mathrm{~mL}, \mathrm{Ca}\left(\mathrm{NO}_{3}\right)_{2}\left(0.5 \mathrm{mmol} \mathrm{Ca} \mathrm{L}{ }^{-1}\right)$ and deionised water to bring the volume to $25 \mathrm{~mL}$. The
Erlenmeyer flasks were fixed on an orbital shaker (IKA $\mathrm{KS} 260$ control) for $24 \mathrm{~h}$ at $200 \mathrm{rpm}$. The $\mathrm{pH}$ of the solutions was then measured. Duplicate experiments were conducted. The largest error was \pm 0.13 , with a mean of \pm 0.05 . The surface charge, $\sigma\left(\mathrm{C} \mathrm{m}^{-2}\right)$, was calculated using equations described in [38].

\subsection{Equilibrium adsorption isotherms}

Adsorption can be (i) a physical process when electrostatic and coulombic attraction forces bind the adsorbate to the adsorbent, (ii) a chemical process when chemical bonds bind the adsorbate to the adsorbent and (iii) both a physical and a chemical process when both (i) and (ii) occur simultaneously. Consequently, it is of interest to describe the adsorbents both physically and chemically. The characteristics of the adsorbents were investigated to provide two aspects that will be useful in understanding, interpreting and explaining the adsorption results obtained from the experiments.

The experimental results were investigated using various adsorption models, such as Langmuir, Freundlich and Henry isotherms [6, 8, 40-45]. The batch studies on single adsorbate isotherm behaviour were then extended to multicomponent adsorption. The isotherm represents the variation of adsorption with concentration of adsorbate in bulk solution; hence, a graph was produced of the dissolved organic carbon (DOC) load (milligramme of DOC per gram of adsorbent) versus the residual DOC (milligramme per litre). The results showed the adsorption isotherms for both DOC and UV absorbance at $254 \mathrm{~nm}$. All experiments were run in duplicate and were found to be reproducible. The results of the kinetic studies [12], indicated that equilibrium is reached in 4 days when the adsorbents are mixed with the HS solution. Therefore, results presented in this paper correspond to equilibrium analyses performed, using a centrifuge at $200 \mathrm{rpm}$, after 4 days contact between the adsorbate (HS) and the abovementioned adsorbents.

The commercial humic acid acquired from Aldrich was weighed until $10 \mathrm{~g}$ and was dissolved in deionized water (2 L). The solution was centrifuged for $2.5 \mathrm{~h}$ at $10,000 \mathrm{rpm}$. The supernatant was obtained from the flasks and was filtered. Various types of filters were used which include Whatman glass microfiber GF/F, GF/B, GF/C of 2.5, 1.2 and $0.7 \mu \mathrm{m}$ sizes respectively and cellulose acetate of $0.45 \mu \mathrm{m}$ and Whatman number $3(6 \mathrm{~mm})$. The filtered solution was used as stock for more fractionation.

The HS solution $(250 \mathrm{~mL})$ was mixed with a fixed mass of adsorbent in a conical flask. The investigation of adsorption capacity was done at different doses and contact times (0$168 \mathrm{~h}$ ). A solution without any adsorbent was used as a control. The mixture was mixed at $200 \mathrm{rpm}$. After given time, the samples were removed from shaker and were filtered and analysed for UV absorbance. Furthermore, DOC analyser 
(Dohrman DC-80 Carbon Analyser) was employed to measure DOC content of the samples. All the experiments were conducted at $19 \pm 0.5^{\circ} \mathrm{C}$.

\section{Results and discussion}

\subsection{Surface area and pore size analyses}

The different types of HS in wastewaters vary chemical and physical properties, and, as a result, they interact contrarily with different types of adsorbents. Regarding the adsorbents porosity, GAC is mainly microporous, with a very large surface area. The situation for $\beta-\mathrm{FeOOH}$ is unclear, since different methods give different results (Table 1); nevertheless, microporosity is most likely to be present on the iron compounds. From Table 1, the area available for adsorption on AAFS and $\beta$-FeOOH is small compared with GAC. However, the size of the adsorbate may make it unable to penetrate micropores, hence, inhibiting adsorption onto GAC.

\subsection{Fourier transform infrared spectroscopy}

FTIR is as an important technique for the investigation of the interaction between the functional groups on the adsorbent's surface with the adsorbate. Figure 1 shows the FTIR spectrum of GAC, AAFS and $\beta$-FeOOH. It can be noticed that all spectra (GAC, AAFS and $\beta-F e O O H)$ display a band between 2350 and $2310 \mathrm{~cm}^{-1}$ which is due to adsorption of atmospheric carbon dioxide. For GAC, this band is band (b). Band (a) at $3430 \mathrm{~cm}^{-1}$ is due to $\mathrm{OH}$ stretching, and the $\mathrm{CO}$ stretching of the alcohol group is found between 1160 and $1000 \mathrm{~cm}^{-1}$ (band (e)). Band (c) at $1550 \mathrm{~cm}^{-1}$ comes from the stretching of double bonds $\mathrm{C}=\mathrm{C}$ in aromatic rings and from the $\mathrm{C}=\mathrm{O}$ and $\mathrm{COO}^{-}$stretching. Absorption of the $\mathrm{C}-\mathrm{O}$ stretch and $\mathrm{OH}$ deformation is around $1450 \mathrm{~cm}^{-1}$ (band (d)) [46]. According to
[46], band shifts are most likely present due to factors such as intramolecular and intermolecular bonding, steric effect and degree of conjugation [46]. This makes difficult the precise assignment of each small band within those regions of the spectrum, which is why the global structure is identified from regional absorption only.

The FTIR spectra of AAFS display bands at identical wavenumbers. Band (a) in the region $3600-3000 \mathrm{~cm}^{-1}$ is attributed to strong hydrogen bonds and hydroxyl groups stretching vibrations. These represent lattice water, $\mathrm{M}-\mathrm{OH}$ (M represents a metal) and hydroxocomplexes. Adsorption of atmospheric carbon dioxide appears again at $2310 \mathrm{~cm}^{-1}$ (band (b)). Band (c) at $2085 \mathrm{~cm}^{-1}$ is an overtone of band (h) at $1075 \mathrm{~cm}^{-1}$, itself due to $\mathrm{Al}=\mathrm{O}$ stretching [47].

The small shoulder at $1950 \mathrm{~cm}^{-1}$ (band (d)) could be due to $\mathrm{Fe}-\mathrm{H}$ bond [48]. Band at $1643 \mathrm{~cm}^{-1}$ could be attributed to the bending of water molecule bonds $\mathrm{H}-\mathrm{O}-\mathrm{H}$, centred on $1630 \mathrm{~cm}^{-1}$.

Absorption band f at $1500 \mathrm{~cm}^{-1}$ is due to carbonyl compounds, and band $(\mathrm{g})$ at $1385 \mathrm{~cm}^{-1}$ is attributed to carbonate ions in the presence of iron [48]. $\mathrm{OH}$ stretching and $\mathrm{H}$ bonds absorb in the range of 3600 to $3000 \mathrm{~cm}^{-1}$ (band (a), very broad). Fe-H bonds absorb around 2000-1900 $\mathrm{cm}^{-1}$ (band (b)) and the $\mathrm{H}-\mathrm{O}-\mathrm{H}$ bending mode absorbs at $1610 \mathrm{~cm}^{-1}$ (band (c)). Bands, (d) at $1480 \mathrm{~cm}^{-1}$ and band (e) at $1340 \mathrm{~cm}^{-1}$ are attributed to carbonyl compounds and carbonate ion $\mathrm{CO}_{3}{ }^{-}$. Absorption bands (f) $\left(1100 \mathrm{~cm}^{-1}\right)$ and $(\mathrm{g})$ $\left(1060 \mathrm{~cm}^{-1}\right)$ are attributed to aquo- and hydroxocomplexes absorbing between 1200 and $600 \mathrm{~cm}^{-1}$ [48]. Usual characteristics of the akaganeite structure are two absorption bands around $690 \mathrm{~cm}^{-1}$ (band (h)) and $430 \mathrm{~cm}^{-1}$. However, absorption bands below $700 \mathrm{~cm}^{-1}$ are not clear, and these bands are difficult to identify, most likely due to the weak transmittance in the presence of water in the hydrophilic ferric oxihydroxide. For this akaganeite $\beta-\mathrm{FeOOH}$, the hydroxyl $\mathrm{OH}$ is the dominant absorbing group.

Table 1 Summary of the physical characteristics of the adsorbents determined using nitrogen adsorption at $77 \mathrm{~K}$

\begin{tabular}{llll}
\hline Characteristic & GAC & AAFS & $\beta-F e O O H$ \\
\hline $\mathrm{S}_{\mathrm{BET}}\left(\mathrm{m}^{2} \mathrm{~g}^{-1}\right)$ & 980 & 286 & 360 \\
$\mathrm{t}$ method & & & 0 \\
$\quad$ Micropore area $\left(\mathrm{m}^{2} \mathrm{~g}^{-1}\right)$ & 812 & 0 & 0 \\
Micropore volume $\left(\mathrm{cm}^{3} \mathrm{~g}^{-1}\right)$ & 168 & 0 & 360 \\
External area $\left(\mathrm{m}^{2} \mathrm{~g}^{-1}\right)$ & 0.37 & 286 & 3.5 \\
BJH method & & 3.5 (medium) & $($ narrow and strong) \\
Pore diameter at peak value & 3.5 (very weak) & & \\
$(\mathrm{nm})$ & 2.2 (very strong) & & 2.38 \\
HK method & 1.13 & 0.55 & 0.30 \\
Median pore width $(\mathrm{nm})$ & 0.48 & 36 & 51 \\
Maximum pore volume $\left(\mathrm{cm}^{3} \mathrm{~g}^{-1}\right)$ & 94 & 0.34 & \\
Micropore volume $(\%<2.5 \mathrm{~nm})$ & & \\
\hline
\end{tabular}


Fig. 1 FTIR spectra of GAC, AAFS and B-FeOOH
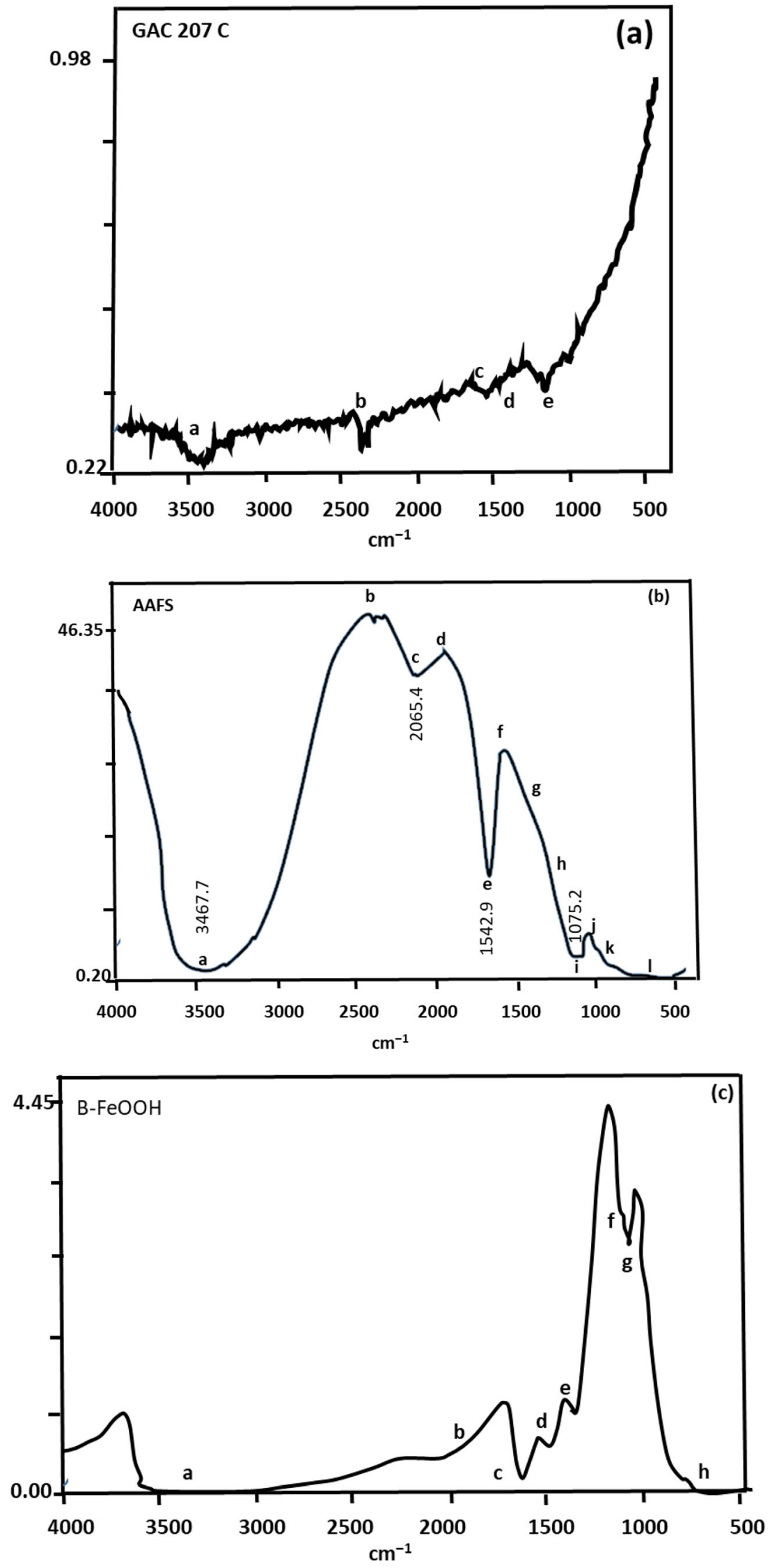


\subsection{Point of zero charge, $\mathrm{pH}_{\mathrm{zpc}}$}

Adsorbents are neutral compounds although their surface can be electrically charged according to the surface functional groups and to the $\mathrm{pH}$ of the water with which they are in contact. Figure 2 shows the surface charge with $\mathrm{pH}$ for $\mathrm{GAC}$, AAFS and $\beta-\mathrm{FeOOH}$.

When calcium nitrate is used, the $\mathrm{pH}_{\mathrm{zpc}}$ are at $\mathrm{pH} 10.6,5.0$ and 5.4 for GAC, AAFS and $\beta-\mathrm{FeOOH}$, respectively. These values are very close to the $\mathrm{pH}$ values before any addition of acid or base, which were 10.8, 5.4 and 5.8 for the same compounds, particularly, when taking into account the error on $\mathrm{pH}$ to be \pm 0.1 . The $\mathrm{pH}_{\mathrm{zpc}}$ values of both iron compounds are very close. This could be attributed to the presence of iron, since in general, alumina have higher $\mathrm{pH}_{\mathrm{zpc}}$ values. Boehmite is part of the activated alumina, and, as an aluminium oxihydroxide, it has some similarities with iron oxihydroxide $(\beta-\mathrm{FeOOH})$; $\mathrm{Fe}^{3+}$ can actually replace $\mathrm{Al}^{3+}$ in the boehmite crystal lattice [49] which explains why their $\mathrm{pH}_{\mathrm{zpc}}$ values are very close. The hydroxyl groups of oxihydroxide metal-OOH provide both acidic and basic functionalities to the media. As for the GAC, its basic functionality is dominant. When adding the GAC to deionised water only, the $\mathrm{pH}$ was raised from 5.5 to 10.9. This $\mathrm{pH}$ increase is evidence of the adsorption either of the protons on the GAC surface or of the release of the hydroxyl groups from the surface. Comparatively, the addition of AAFS to deionised water only slightly decreased the $\mathrm{pH}$, which was attributed to the deprotonation of $\mathrm{AlOH}$. The $\mathrm{pH}$ slightly increased for $\beta$-FeOOH under the same conditions. Since the surface was also negative at $\mathrm{pH} 5.8$, it could be interpreted that some $\mathrm{FeO}^{-}$sites re-associated to become $\mathrm{FeOH}$. The equations below (3,4 and 5) show the
Fig. 2 Surface charge versus $\mathrm{pH}$ for GAC, AAFS and B-FeOOH
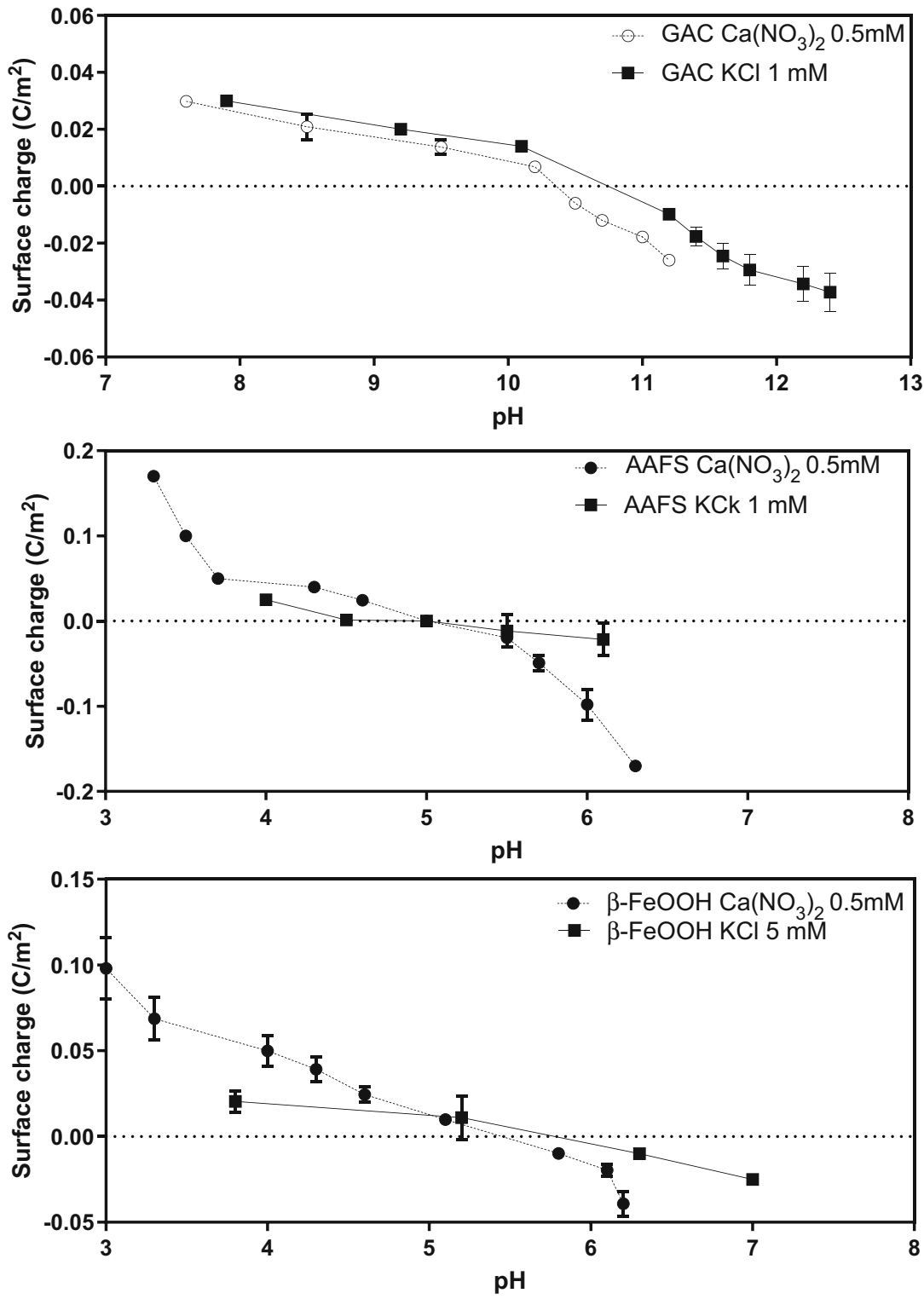
chemisorption of calcium on AAFS and $\beta-\mathrm{FeOOH}$ [49]. Hence, calcium replaces the protons on the surface, and aluminium (AAFS) could be swapped for iron $(\beta-\mathrm{FeOOH})$ :

$\mathrm{AlOH}+\mathrm{Ca}^{2+} \leftrightarrow \mathrm{AlOCa}^{+}+\mathrm{H}^{+}$

The possibly displacement of two protons:

$$
\begin{aligned}
& \mathrm{AlOH}+\mathrm{Ca}^{2+}+\mathrm{H}_{2} \mathrm{O} \quad \leftrightarrow \quad \mathrm{AlOCaOH}+2 \mathrm{H}^{+} \\
& 2 \mathrm{AlOH}+\mathrm{Ca}^{2+} \leftrightarrow(\mathrm{AlO})_{2} \mathrm{Ca}+2 \mathrm{H}^{+}
\end{aligned}
$$

Therefore, it could be concluded that calcium ions have been adsorbed on the surface, shielding the negative charges. $\mathrm{Ca}^{2+}$ was adsorbed on the medium; it can either screen the adsorption site and inhibit HS adsorption, or act as a ligand between the organic matter and the adsorbent, thereby, increasing the adsorption. The reported $\mathrm{pH}_{\mathrm{zpc}}$ values for GAC vary from 2.1 to 9.7 according to the activation treatment and origin of the GAC [50]. The GAC used in this study has a higher $\mathrm{pH}_{\mathrm{zpc}}$ and is more basic, confirmed by a domination of $\mathrm{OH}$ groups detected from the FTIR spectroscopy. To confirm the results, the surface charge of the adsorbents was measured using a different electrolyte at a higher concentration, namely potassium chloride $\mathrm{KCl}$ at $0.001 \mathrm{~mol} / \mathrm{L}$. This new concentration brings the same amount of charges since $\mathrm{K}^{+}$is monovalent and $\mathrm{Ca}^{2+}$ is divalent. However, using $\mathrm{KCl}$ instead of $\mathrm{Ca}\left(\mathrm{NO}_{3}\right)_{2}$ has only brought a slight change in $\mathrm{pH}_{\text {zpc }}$ values. The $\mathrm{pH}_{\mathrm{zpc}}$ shifted from 5.0 to 5.3 for AAFS and from 5.4 to 5.9 for $\beta-\mathrm{FeOOH}$. This confirms the role of calcium in decreasing the apparent surface charge of the iron compounds due to its affinity for the surface. The $\mathrm{pH}_{\mathrm{zpc}}$ of GAC has shifted from 10.6 with $\mathrm{Ca}\left(\mathrm{NO}_{3}\right)_{2}$ down to 10.4 with $\mathrm{KCl}$, showing a different behaviour from the other two adsorbents. The GAC surface was also slightly negative initially $(\mathrm{pH}=$ 10.8). However, in this case, the surface has the same sensitivity towards calcium nitrate and potassium chloride. During the equilibrium adsorption studies, all experiments were carried out at $\mathrm{pH}$ 7.0. Therefore, the GAC surface charge is positive with a value of $+0.04 \mathrm{C} / \mathrm{m}^{2}$. An estimation of the iron compound surface charge was made using a four degree polynomial function $\left(R^{2}=0.996\right)$, and the results at $\mathrm{pH} 7.0$ were $0.5 \mathrm{C} / \mathrm{m}^{2}$ for AAFS and $-0.1 \mathrm{C} / \mathrm{m}^{2}$ for $\beta-\mathrm{FeOOH}$.

\subsection{Physical characteristics of the adsorbents}

Table 2 shows the bulk density, grain density, porosity and median size of the adsorbents.

For GAC, the poured porosity would be expected to be the highest due to bigger grains, although this can be compensated for by the shape of the grains, which are mostly "torn-broken" compared with "angled" for the other adsorbents. The GAC and AAFS have similar porosity when taking into account the error of \pm 0.01 on the last digit. However, it is clear that $\beta$ -
Table 2 The bulk density, grain density, porosity and median size of the adsorbents

\begin{tabular}{llll}
\hline Adsorbent & GAC & AAFS & $\begin{array}{l}\beta- \\
\text { FeOOH }\end{array}$ \\
\hline Bulk density $\left(\mathrm{kg} \mathrm{L}^{-1}\right)$ & 0.44 & 0.89 & 1.32 \\
Grain density $\left(\mathrm{kg} \mathrm{L}^{-1}\right)$ & 0.90 & 1.78 & 2.26 \\
Packed porosity & 0.46 & 0.47 & 0.34 \\
Effective diameter $\left(\mathrm{d}_{10}\right)(\mathrm{mm})$ & 0.63 & 0.33 & 0.36 \\
Median diameter $\left(\mathrm{d}_{50}\right)(\mathrm{mm})$ & 0.91 & 0.41 & 0.56 \\
$\mathrm{~d}_{90}(\mathrm{~mm})$ & 1.15 & 0.5 & 0.94 \\
\hline
\end{tabular}

$\mathrm{FeOOH}$ is much less porous than GAC and AAFS (Table 2). Porosity on activated media comes from heating the material at high temperatures. Artificial preparation of $\beta-\mathrm{FeOOH}$ does not involve such an activation step [51]. Instead, it was precipitated from $\mathrm{FeCl}_{3}$ solution, which when left for a few hours, produces rod shape crystals. Therefore, the absence of activation is considered responsible for the less porous structure. However, it is interesting to compare it with the packed porosity. Packed porosity is much smaller than poured porosity for $\beta-\mathrm{FeOOH}$, and this is likely to bring a large variation in the porosity of the adsorbent bed and on the adsorption capacity, particularly when submitted to the weight of the water column.

\subsection{Scanning Electron microscopy}

Figure 3 shows the SEM images of the adsorbents. The torn edges of the grains of GAC also showed the internal "holes". Its internal structure could be recognised as graphite type layering of carbon sheets. Pores created from the activation process and the extensive debris account for the friability of this adsorbent. Grains of AAFS showed identical angled shape with a surface that appeared smooth with a uniform coating. On the bigger scale, only few cracks or holes are visible which suggests the surface area to be mainly external. The surface of $\beta-\mathrm{FeOOH}$ appeared smooth with an abundance of debris due to its high friability. The porous structure agreed well with the SEM photographs (Fig. 3) which illustrate the sheet structure of GAC and its numerous cavities in contrast with the iron compounds, which appear smooth with only a few cracks. Pores created from the activation process and the extensive debris account for the friability of this adsorbent. Considering the scale, mesopores and macropores are seen on the photographs (sizes above $2.5 \underline{\mu m}$ ). The surface of $\beta$ $\mathrm{FeOOH}$ appears smooth with an abundance of debris due to its high friability. The scale does not allow one to distinguish the characteristic rod-cigar shape of akaganeite crystallites ( $\beta$ form of $\mathrm{FeOOH}$ ). 


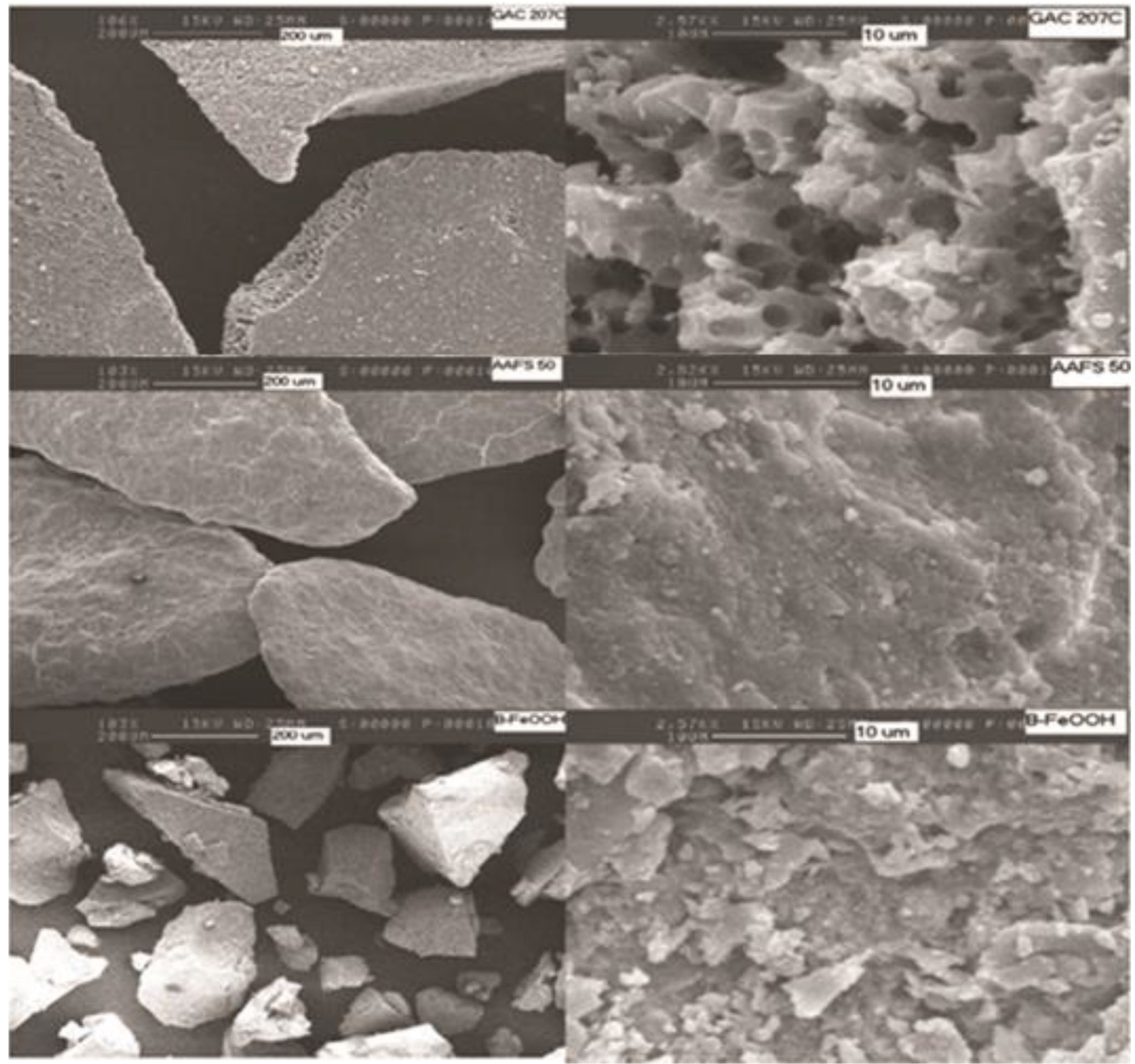

Fig. 3 SEM of GAC, AAFS and $\beta$-FeOOH

\subsection{Equilibrium adsorption isotherms and mechanisms of adsorption}

It is necessary to take into account the ionic surrounding of humic substances since charge effects, make the molecules expand due to intramolecular charge repulsion. On the other hand, intermolecular repulsion, together with dragging action of the counter ions, also alters the molecules' movement. Aquatic humic substances were found to have $22.9 \%$ of the molecular weight distribution above 10,000 $\mathrm{Da}$ and $46.3 \%$ below $1000 \mathrm{Da}$. An aerated groundwater was also found to have a large proportion of its DOC (61\%) falling within the range of molecular weight between 4000 and 10,000 Da, although this was justified since groundwater contains more soil-like humic substances than superficial waters [35-37].

\subsubsection{Fraction $\mathrm{F} 1(<5 \mathrm{kDa})$}

Figure 4 shows the adsorption of fraction $\mathrm{F} 1$ for $\mathrm{UV}_{254}$ and DOC. GAC largely adsorbed F1 whereas iron compounds did not. The two striking features of the adsorption isotherms in UV and DOC are (i) the difference in the first region (where residual concentration is low) and (ii) the low loads on AAFS and $\beta-\mathrm{FeOOH}$ compared with GAC. The first region indicates how strong the interactions are between the adsorbate and the adsorbent. The high load on GAC from a very low residual

鱼 Springer 
Fig. 4 Equilibrium Isotherms for $\mathrm{GAC}, \mathrm{AAFS}$ and $\mathrm{B}-\mathrm{FeOOH}$
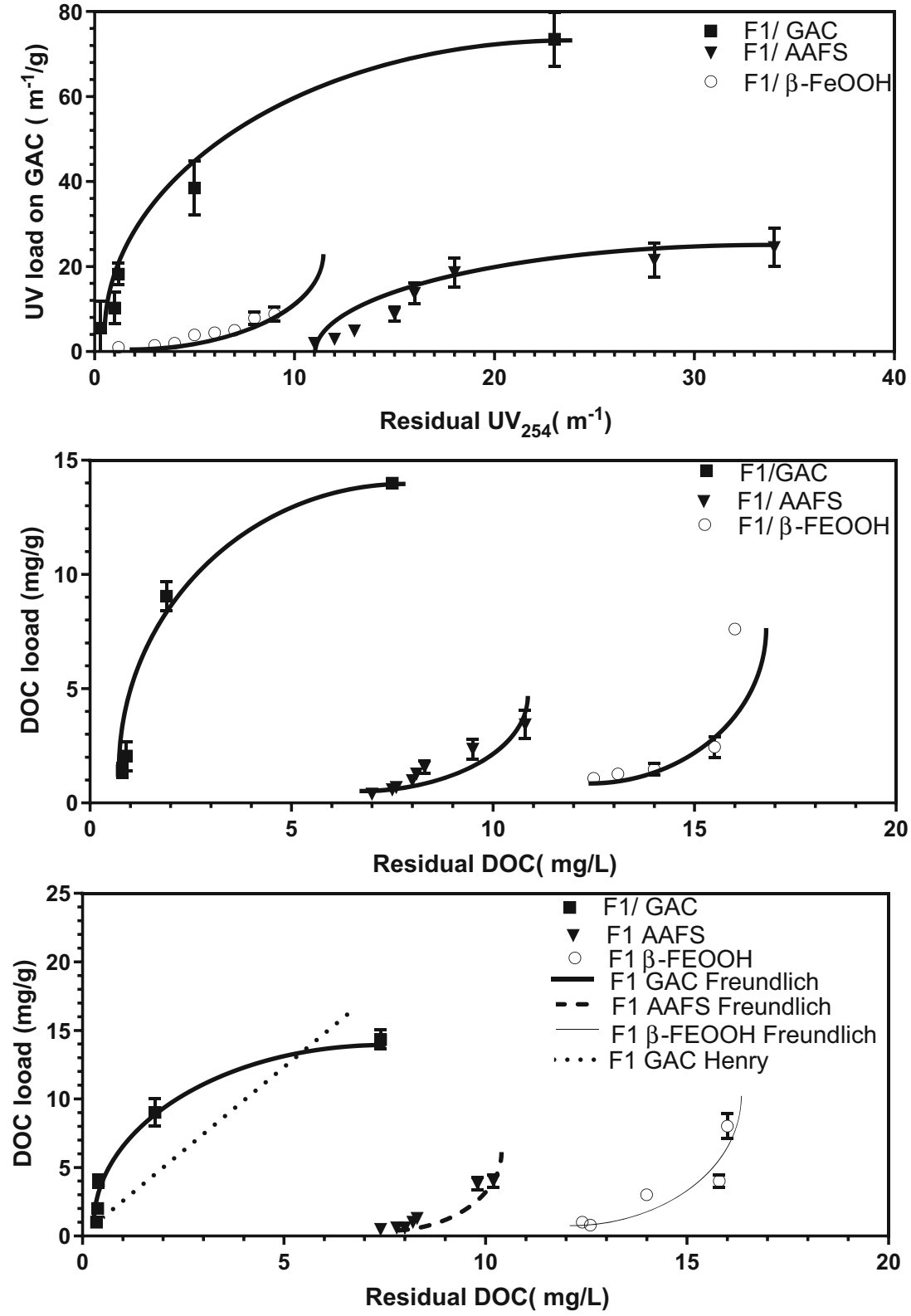

concentration showed the strong affinity of the lowest MW on the GAC surface. It was shown that F1 could be classified as a hydrophilic fraction. However, fulvic acids are generally part of the hydrophobic substances, and hydrophilic matter refers to the substances with a MW below $500 \mathrm{Da}$. The tendency of F1 to adsorption is equivalent to F1 "escaping" from the water, which confirms its dominant hydrophobic aspect. Cook and Langford [52] showed the fulvic acids to be much functionalised with many carboxylic groups and aliphatic structures. At $\mathrm{pH} 7$, they lose their protons, and, since GAC is highly positive $\left(\mathrm{pH}_{\mathrm{zpc}}\right.$ is 10.7$)$, strong links are favoured. At neutral $\mathrm{pH}, \mathrm{GAC}$ is positive, and complexation might occur more through the inner sphere corresponding to a high affinity of F1 for the surface, favouring a strong adsorption.
For $\beta-\mathrm{FeOOH}$, the $\mathrm{pH}_{\mathrm{zpc}}$ is between 5.0 and 5.5; hence, it acquires a negative surface at $\mathrm{pH} 7$. Ionised fulvic acids face repulsion when approaching the surface. In this case, Vermeer et al. [53] mentioned the specific interactions such as ligand exchange, accompanying possible coulombic forces on the surface. The AAFS grains were initially brown with white spots where $\beta-\mathrm{FeOOH}$ coating was not complete and left the $\mathrm{Al}_{2} \mathrm{O}_{3}$ surface bare. By the end of the experiments, the whole surface of the grains was dark brown due to the HS adsorption. From such observations, it can be concluded that the adsorption is mainly external. A suggested cause of the low adsorption on AAFS is that the low microporosity is not accessible for low $\mathrm{MW}$ of $\mathrm{F} 1$. Gyration radius $\mathrm{R}_{\mathrm{G}}$ of a molecule 
represents the radius of the sphere swept by the same molecule when turning on itself. $R_{\mathrm{G}}$ of $\mathrm{F} 1$ molecules is between 1.5 and $2 \mathrm{~nm}$. GAC is mainly microporous with most pores smaller than $2.2 \mathrm{~nm}$ and a median pore size of $1.13 \mathrm{~nm}$. Conversely, AAFS and $\beta-\mathrm{FeOOH}$ are mainly mesoporous $(>2.5 \mathrm{~nm})$ but present little microporosity. At these sizes, F1 is able to enter most pores of the three adsorbents under study, but the smallest pores of GAC remaining inaccessible. For GAC, this corresponds well with the second region of adsorption on the isotherm. Figures 4 shows a slow approach to a plateau; this level corresponds to saturation. It indicates that, when the media is mainly microporous, a favourable monolayer adsorption is completed [54]. For $\beta-\mathrm{FeOOH}$, adsorption did not take place immediately, although the pore size is not a limiting factor. Therefore, only a few adsorption sites are favourable to adsorption of low MW (different energy of adsorption involved). At $\mathrm{pH} 7$ for AAFS, the surface presented positive charges. Consequently, it can attract HS, and this explains the high loads on AAFS compared with $\beta-\mathrm{FeOOH}$. Low adsorption on $\beta-\mathrm{FeOOH}$ is also likely to be due to relatively few sites being favourable for adsorption of low MW HS [53]. As the $\mathrm{pH}$ increased to 8 , the slope decreased and the adsorbent-adsorbate interactions, initially of coulombic nature, became more and more specific (ligand exchange). Since the concentration range is wide (residual concentration up to $250 \mathrm{mgL}^{-1}$ ), the strong intermolecular repulsion, within the solution, causes the HS to reach for the surface. This is probably the reason for the adsorption observed on $\beta-\mathrm{FeOOH}$ occurring only at high residual concentration. Therefore, the electrostatic effect did not control the adsorption under the conditions of this work. However, strong adsorption via ligand exchange, by inner sphere coordination, can also take place where positive charges are available on the iron mineral. The second interesting feature on Fig. 4 is the difference between the adsorption load on $\beta-\mathrm{FeOOH}$ when comparing $\mathrm{UV}_{254}$ and DOC. A residual $\mathrm{UV}_{254}$ beyond $10 \mathrm{~m}^{-1}$ is necessary before adsorption takes place on AAFS whereas, on $\beta-\mathrm{FeOOH}$, residual $\mathrm{UV}_{254}$ needs to be approximately $2.5 \mathrm{~m}^{-1}$ only. This is attributed to the SUVA value (depicts the ratio of UV absorbance $\left(\mathrm{m}^{-1}\right)$ to DOC $\left(\mathrm{mg} \mathrm{L}^{-1}\right)$ values. It is a good indicator of organic matter composition and reactivity changes. SUVA was 0.9 for F1 used on $\beta$-FeOOH versus 3.4 for F1 used on AAFS, due to the difficulty in making solutions with identical characteristics for consecutive experiments. It indicates that the solution has a high DOC but a low UV absorbance, as seen from the residual concentrations on both graphs. It particularly showed that F1 may be subdivided much further in more MW ranges. As a conclusion, it appeared necessary to have a positive surface for adsorption of low MW HS, which occurred only for GAC. In addition, the high microporosity of GAC provided a large surface for adsorption, as long as heavy MW HS do not block the pores. This did not happen for $\beta-\mathrm{FeOOH}$. It is then only from a high solution concentration, that adsorption is observed since the deprotonated HS repel each other. In this situation, the most likely mechanism for adsorption was the outer-sphere complexation by the long-range Van der Waals forces. This is the case here since $\beta-\mathrm{FeOOH}$ was a negative surface at neutral $\mathrm{pH}$. Therefore, it seems likely that the interaction involved the non-ionised groups of $\beta$ $\mathrm{FeOOH}$ with the functional group of $\mathrm{F} 1$ and, to a lesser extent, the inner-sphere coordination via positive charges on the mineral surface. The Langmuir model was not applicable since no trend of linearity was observed between $\mathrm{C}_{\mathrm{e}} / \mathrm{q}_{\mathrm{e}}$ vs $\mathrm{C}_{\mathrm{e}}$. The Henry model was applied only to the GAC, though the fitting was not good). On the range of the concentration studied, only the Freundlich model could be applied to the three adsorbents, although the fitting for $\beta-\mathrm{FeOOH}$ was not good either. Parameters corresponding to the three models are given in Table 3. A high residual DOC must be reached in the solution to observe a low adsorption on those media. The delay in adsorption was more obvious for DOC than for $\mathrm{UV}_{254}$ giving evidence that only the higher molecular weights of $\mathrm{F} 1$ (close to $5 \mathrm{kDa}$ ) are adsorbed on $\beta-\mathrm{FeOOH}$. In this case, since the initial DOC was high $\left(16.17 \mathrm{mg} \mathrm{L}^{-1}\right)$, adsorption would be expected to be high under the accumulation of the HS on the surface. The $\beta-\mathrm{FeOOH}$ adsorption capacity was only $0.43 \mathrm{mg} \mathrm{g}^{-1}$, compared with 9.11 and $2.55 \mathrm{mg} \mathrm{g}^{-1}$ on GAC and AAFS, respectively, when the initial DOC was much lower (approximately $10 \mathrm{mg} \mathrm{L}^{-1}$ ).

The $1 / n$ value (multiplied by 100) corresponds to the percentage of sites having a similar energy (the Freundlich model assumes the existence of a distribution of the sites energy) [38]. It could be interpreted that at a higher $1 / n$ value, the same reasoning is applicable and all sites are similar. This corresponds to a homogeneous surface. For GAC, $1 / n$ is equal to 0.5 indicating a wide range of sites corresponding to different energies of adsorption. However, the $1 / n$ value would be higher if the delay in adsorption were not taken into account since initially the load increases sharply. The short delay showed that adsorption is observed from a residual DOC of approximately $0.7 \mathrm{mg} \mathrm{L}^{-1}$. This DOC is attributed to the nonadsorbable portion of fraction $\mathrm{F} 1$. The high $1 / n$ value on AAFS (5.75), on the other hand, is due to a slow increase in adsorption, followed by a very sharp increase for the solutions with a high DOC. Although the $1 / n$ value for $\beta-\mathrm{FeOOH}$ is not very high $(0.71)$, the similar shape might lead to a similar conclusion. The very long delay in the adsorption behaviour showed that, whatever the energy of the adsorption sites, they did not present any affinity to the HS molecules below $5 \mathrm{kDa}$ until a high solution concentration took place. 


\subsubsection{Fraction F2 (5-10 kDa)}

Figure 5 shows the adsorption isotherms of $\mathrm{F} 2$ for $\mathrm{UV}_{254}$ and DOC onto AA, AAFS and $\beta-\mathrm{FeOOH}$. It is noticeable that the isotherms shapes are very different from F1. Examining the first region of adsorption, it is clear that $\mathrm{UV}_{254}$ is adsorbed immediately on $\beta$ - $\mathrm{FeOOH}$. However, a slight delay is observed for the DOC, and the isotherm resembles more closely to type IV. This indicated that the heavier molecules of F2 (the one which absorb UV) are removed more efficiently on $\beta$ $\mathrm{FeOOH}$ than the lighter ones of F2. For both UV and DOC, a sharp start of the isotherms on AAFS and $\beta-\mathrm{FeOOH}$ contrasts with the low slope for GAC.

Since GAC has mainly micropores, it could be inferred that GAC would adsorb F2 better if it had a higher proportion of mesopores and perhaps some macropores. It also becomes apparent that for efficient adsorption, interaction of the HS with AAFS and $\beta-\mathrm{FeOOH}$ at $\mathrm{pH} 7$ is possible only for MW above $5 \mathrm{kDa}$. Fraction F2 tends to escape from the water more than fraction $\mathrm{F} 1$ due to less ionisable groups (less carboxylic groups than in F1). The HS in fraction F2 are too big to diffuse into micropores and need meso- or macropores, present in iron compounds, to be adsorbed efficiently. However, it is also possible that the number of sites used for adsorption is the same as for F1. In such a situation, having one heavy MW humic molecule adsorbed has more consequence on the residual concentration than having a small MW molecule adsorbed. Two possibilities are suggested: (i) one heavy molecule occupies one site and, as a consequence, adjacent humic molecules are repulsed towards the solution and (ii) the humic molecule occupies several sites.

For both AAFS and GAC, type $\mathrm{V}$ with a sharp rise of the load when the residual DOC increases was observed. It indicates that adsorption took place beyond a monolayer. In the third region of the adsorption (high residual DOC), the high concentration of the HS brought a change in their behaviour. Since the $\mathrm{pH}$ of the solution was 7, the HS tended to lose their protons and therefore can strongly repel each other and escape onto the positive surface of GAC. In turn, GAC becomes saturated, and the load increased steeply. This also indicated that the heavier MW either displaced lighter MW or blocked the pores. The greater adsorption of heavier MW also corresponded with the higher content of phenolic groups. The external surface of GAC is much less than AAFS and $\beta$-FeOOH $\left(168 \mathrm{~m}^{2} \mathrm{~g}^{-1}\right.$ compared with 286 and $360 \mathrm{~m}^{2} \mathrm{~g}^{-1}$ for AAFS and $\beta-\mathrm{FeOOH}$, respectively). Therefore, the adsorption of bigger molecules on AAFS and $\beta-\mathrm{FeOOH}$ is more favoured than it was for F1.

At $\mathrm{pH} 3.8$, half of the carboxylic acid is dissociated and increasingly so as $\mathrm{pH}$ increases, whereas the $\mathrm{pH}$ needs to reach 10.0 to have half of the phenol dissociated. At $\mathrm{pH} 7$, the carboxylic groups of the HS are mostly ionised as hardly any phenolic groups are dissociated. Therefore, on the
Table 3 Adsorption isotherm parameters for F1 on GAC, $\mathrm{AAFS}$ and $\beta-\mathrm{FeOOH}$

\begin{tabular}{|c|c|c|c|c|c|c|c|}
\hline \multirow[b]{2}{*}{ Adsorbent } & \multirow[b]{2}{*}{$\begin{array}{l}\text { Initial } \\
\text { DOC } \\
\left(\mathrm{mgL}^{-1}\right)\end{array}$} & \multicolumn{3}{|c|}{ Freundlich model } & \multicolumn{2}{|c|}{ Langmuir model } & \multirow{2}{*}{$\begin{array}{l}\text { Henry model } \\
\mathrm{K}_{\mathrm{H}} \\
\left(\mathrm{L} \mathrm{g}^{-1}\right)\end{array}$} \\
\hline & & $\begin{array}{l}\mathrm{K}_{\mathrm{F}} \\
\left(\mathrm{mg} \mathrm{g}^{-1}\right) . \\
\left(\mathrm{mgL}^{-1}\right)^{\mathrm{n}}\end{array}$ & $1 / \mathrm{n}$ & $\begin{array}{l}\text { Adsorption } \\
\text { Capacity }^{(*)} \\
\left(\mathrm{mg} \mathrm{g}^{-1}\right)\end{array}$ & $\mathrm{b}\left(\mathrm{L} \mathrm{mg}^{-1}\right)$ & $\begin{array}{l}\mathrm{Q}_{\mathrm{mon}} \\
\left(\mathrm{mg} \mathrm{g}^{-1}\right)\end{array}$ & \\
\hline \multicolumn{8}{|l|}{ F1 } \\
\hline GAC & 10.48 & 5.55 & 0.51 & 9.11 & $<0$ & $<0$ & 2.121 \\
\hline AAFS & 10.96 & $<10^{-2}$ & 5.75 & 2.55 & $<0$ & $<0$ & NA \\
\hline $\mathrm{B}-\mathrm{FeOOH}$ & 16.99 & $<10^{-2}$ & 0.71 & 2.73 & $<0$ & $<0$ & NA \\
\hline \multicolumn{8}{|l|}{$\mathrm{F} 2$} \\
\hline GAC & 11.25 & 1.44 & 0.81 & 5.66 & 0.08 & 19.57 & 0.993 \\
\hline AAFS & 10.93 & 1.08 & 1.23 & 7.18 & $<0$ & $<0$ & 1.718 \\
\hline $\mathrm{B}-\mathrm{FeOOH}$ & 7.08 & 2.50 & 1.05 & 5.02 & $<0$ & $<0$ & 2.322 \\
\hline \multicolumn{8}{|l|}{ F3 } \\
\hline GAC & 13.65 & 0.54 & 0.48 & 1.86 & 0.15 & 2.77 & NA \\
\hline AAFS & 13.61 & 2.55 & 0.41 & 5.45 & 0.29 & 8.71 & NA \\
\hline$\beta-\mathrm{FeOOH}$ & 13.61 & 1.60 & 0.55 & 4.64 & 0.16 & 9.56 & 0.665 \\
\hline \multicolumn{8}{|l|}{ F123 } \\
\hline GAC & 10.64 & 0.30 & 1.02 & 2.72 & 0.007 & 41.49 & 0.300 \\
\hline AAFS & 5.43 & 0.60 & 1.20 & 2.75 & $<0$ & $<0$ & 0.750 \\
\hline$\beta-\mathrm{FeOOH}$ & 8.44 & 1.04 & 0.86 & 3.49 & 0.06 & 18.18 & 1.010 \\
\hline
\end{tabular}

*Experimental load (DOC mg/g of adsorbent) after $96 \mathrm{~h}$, in experiments where the dose was of $1 \mathrm{~g}$ adsorbent $\mathrm{L}^{-1}$ 
Fig. 5 Isotherm comparison of HS removal by GAC, AAFS and $\mathrm{B}-\mathrm{FeOOH}$
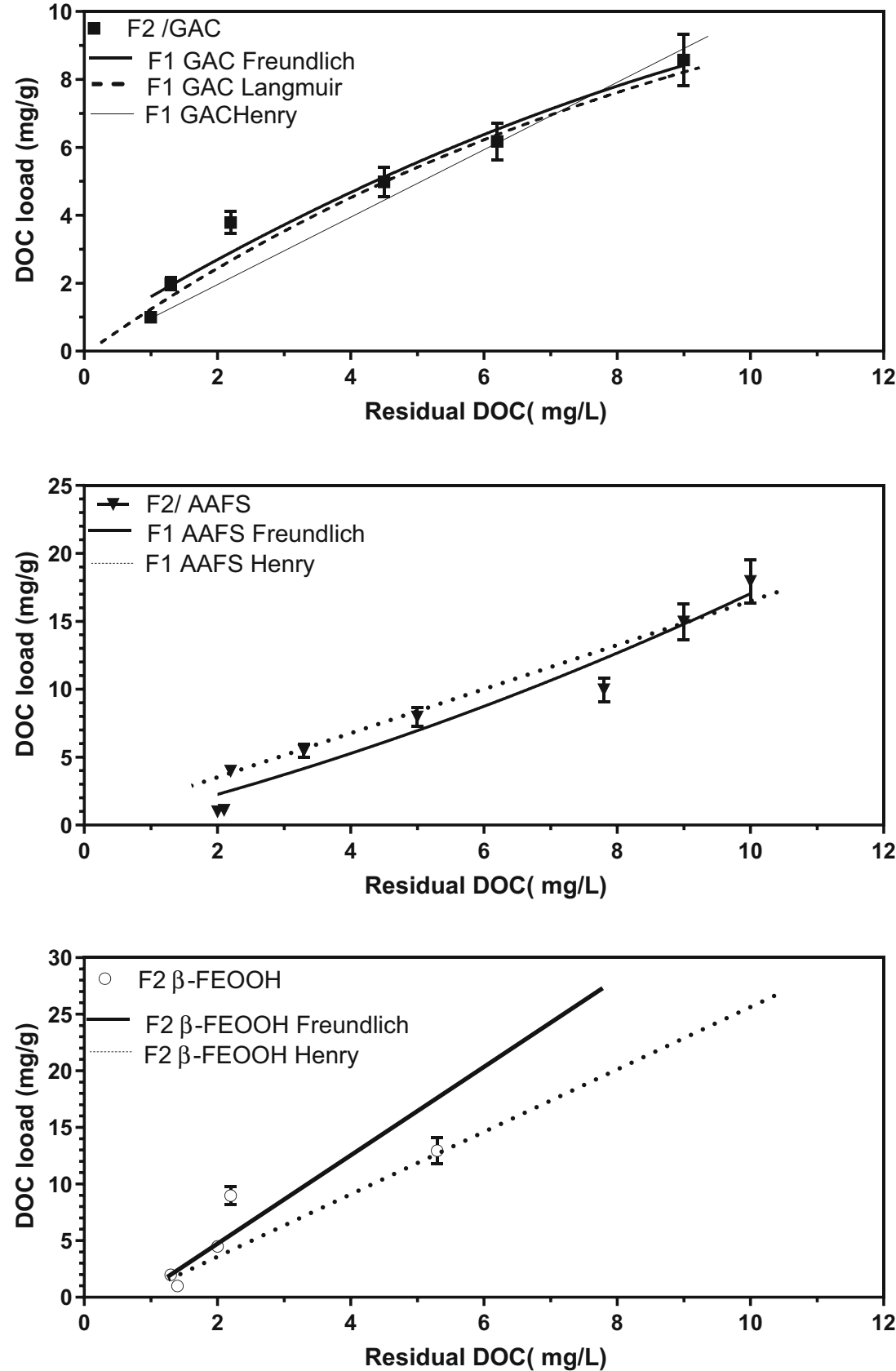

negative surface, less repulsion occurs as more phenolic groups are involved. In addition, the adsorption of the high MW HS is more likely to result in a higher load since only part of the molecule could be adsorbed, leaving free sites for others but contributing to a high proportion of UV and DOC removal.

Figure 5 shows the model fitting for fraction F2 onto GAC, AAFS and $\beta-\mathrm{FeOOH}$. Corresponding parameters are correlated in Table 3. The three models, Langmuir, Freundlich and Henry can be applied successfully to GAC. However, none of the models represented the complete range of data, which is likely to be due to additional surface creation and a precipitation on the surface beyond adsorption phenomena $[48,55]$. As for F1, a slight delay is observed, and adsorption is obvious from a residual DOC of $0.7 \mathrm{mg} \mathrm{L}^{-1}$. For AAFS, the Langmuir model did not fit the experimental data while the Freundlich and Henry models were successfully applied. As for fraction F1, the adsorption delay (due to the non-adsorbable fraction) is not well represented by any of the models. The Freundlich model showed that it is the best model to describe the adsorption of fraction F2 and it can represent a complete range of MW if taking into account a nonabsorbable part of the HS. For $\beta-\mathrm{FeOOH}$, results are 
much dispersed. On the range of DOC studied, Freundlich and Henry's model fitting are similar but become distinct as the residual DOC increased.

Comparing $\mathrm{K}_{\mathrm{F}}$ and $1 / n$ values for $\mathrm{F} 1$, it is clear that $\mathrm{K}_{\mathrm{F}}$ decreased for GAC and the slope $1 / n$ increased, indicating that the energy of adsorption is more uniform. For AAFS and $\beta$ $\mathrm{FeOOH}, \mathrm{K}_{\mathrm{F}}$ and the adsorption capacity increased. This indicated that the adsorption is favourable on these adsorbents and the mechanisms might be the mechanisms (i) and (ii) of Fig. 6 . On the other hand, $1 / n$ approached unity which agrees with the fact that the Henry model could be applied, particularly for $\beta$ $\mathrm{FeOOH}$. Various mechanisms of adsorption simultaneously take place on this path, each of which has a specific resistance to adsorption. The overall kinetics of the process are limited by the largest resistance. Therefore, it is essential to know which mechanism is dominant since the slowest mechanism imposes the kinetics of adsorption.

It also becomes apparent that for efficient adsorption, interaction of HS with iron compounds at $\mathrm{pH} 7$ is possible only for MW above $5 \mathrm{kDa}$. Fraction F2 tends to "escape" from the water more than fraction F1 due to less ionisable groups (less carboxylic groups than in F1). Humic substances in fraction F2 are too big to diffuse into micropores and need meso- or macropores, present in iron compounds, to be adsorbed efficiently. However, it is also possible that the number of sites used for adsorption is the same as for F1. In such a situation, having one heavy MW humic molecule adsorbed has more consequence on the residual concentration than having a small MW molecule adsorbed. Two possibilities are suggested: (i) one heavy molecule occupies one site, and as a consequence, adjacent humic molecules are repulsed towards the solution, and (ii) the humic molecule occupies several sites.

\subsubsection{Comparisons of model parameters between F1, F2, F3 and F123}

The parameters estimated from Freundlich, Langmuir and Henry models for F1, F2, F3 and F123 are represented in Table 3. The Freundlich model, which allows for a distribution of energy of adsorption, is the only model applicable to each adsorbent/adsorbate system. The adsorbents are most likely to present a heterogeneous surface, a high porosity in GAC and uneven distribution of the local charges on the iron compounds. In addition, variations of natural organic matter in weight and organic functions are expected to adsorb with different energies. These two aspects justify the applicability of the Freundlich model. However, heterogeneity of the surface becomes less obvious as the MW increases, and the adsorption energy is then more uniform $(1 / n$ is closer to 1$)$. The possibility of using $\mathrm{K}_{\mathrm{F}}$ as an indicator of adsorption capacity is confirmed with both parameters following similar trends. It is also clear that the presence of F1 influenced the behaviour of F123. The affinity of F1 for GAC became clear when observing the small difference between the original DOC and the adsorption capacity. For $\beta-\mathrm{FeOOH}$, the very large difference indicated the low affinity of F1 for this iron compound (Fig. 7).

(i)
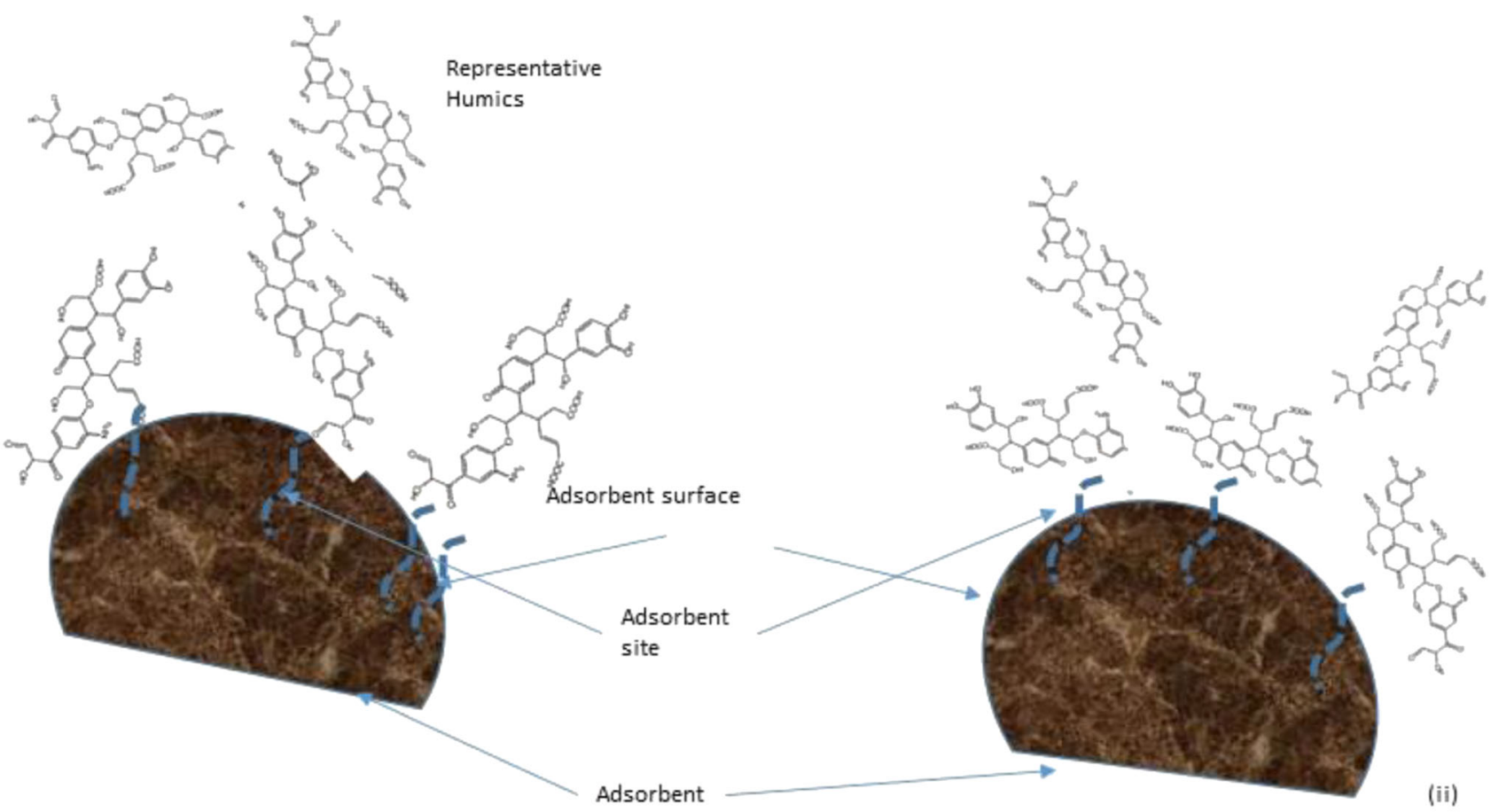

Fig. 6 Adsorption mechanism

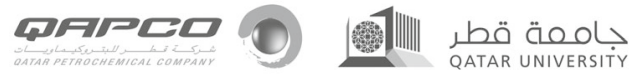


Fig. 7 Overall comparison of HS removal by GAC, AAFS and B$\mathrm{FeOOH}$
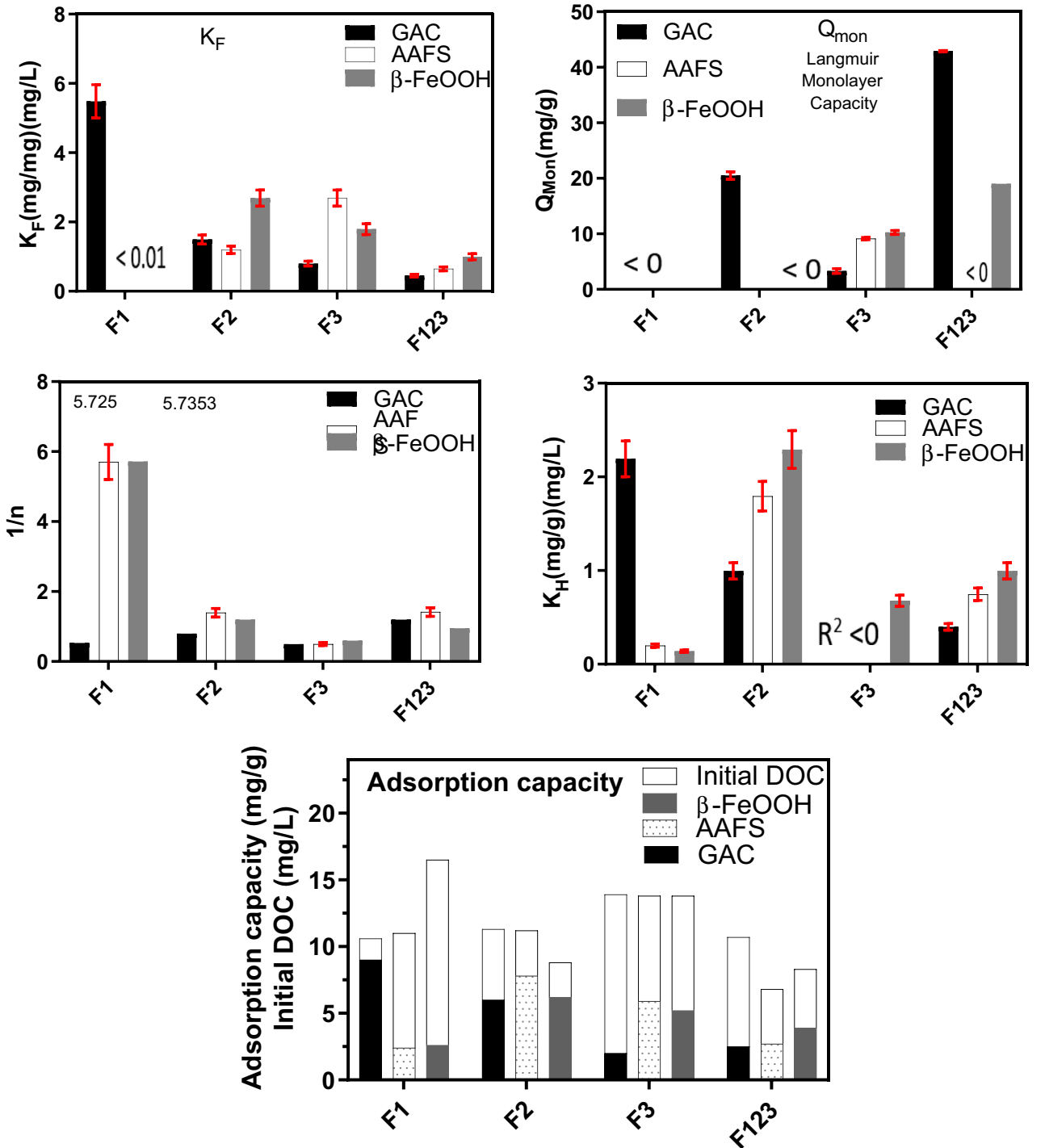

The Langmuir model is generally not suitable; hence, the confirmation that adsorption of the HS required a heterogeneous surface with a distribution of sites energy. F1 is particularly noncompliant to such a model, which is probably due to being the closest in MW to the non-absorbable fraction (very low MW). Henry's model applied to most cases and broadly follows the trend of the Freundlich model. F2 showed regular behaviour on each adsorbent, and the influence of F1 and F3 appeared in the $\mathrm{K}_{\mathrm{H}}$ values for F123 (Fig. 7).

\section{Conclusions}

The following can be concluded:

- Although the FTIR showed that the hydroxyl group was the main surface group on the three adsorbents, the $\mathrm{pH}_{\mathrm{ZPC}}$ showed that GAC is basic and positively charged at
$\mathrm{pH} 7.0$, whereas AAFS and $\beta-\mathrm{FeOOH}$ are more acidic and slightly negatively charged at neutral $\mathrm{pH}$.

- $\quad$ The $\beta$-FeOOH adsorption capacity was only $0.43 \mathrm{mg} \mathrm{g}^{-1}$, compared with 9.11 and $2.55 \mathrm{mg} \mathrm{g}^{-1}$ on GAC and AAFS, respectively.

- F1 is not well adsorbed and only F2 (5-10 kDa) can be efficiently removed by AAFS and $\beta-\mathrm{FeOOH}$. It was strongly suggested that precipitation/condensation occurred on the adsorbent surface.

- It was shown that calcium forms complexes with the HS. Two interactions might have occurred: (i) the number of sites occupied by one molecule of the HS for adsorption can be decreased allowing more sites for others, and (ii) by cancelling some of the negative HS charges, intermolecular repulsion might decrease and allow HS molecules to be closer to one another near the adsorbent surface.

- The Freundlich model fitted all the adsorbent/adsorbate systems. The Langmuir model fitted in a minority of cases 
and was applicable in the second region of adsorption (i.e. neither for low nor high coverage). The Henry model was applicable in most cases in the low range of concentration.

Funding Information Open Access funding provided by the Qatar National Library.

Open Access This article is licensed under a Creative Commons Attribution 4.0 International License, which permits use, sharing, adaptation, distribution and reproduction in any medium or format, as long as you give appropriate credit to the original author(s) and the source, provide a link to the Creative Commons licence, and indicate if changes were made. The images or other third party material in this article are included in the article's Creative Commons licence, unless indicated otherwise in a credit line to the material. If material is not included in the article's Creative Commons licence and your intended use is not permitted by statutory regulation or exceeds the permitted use, you will need to obtain permission directly from the copyright holder. To view a copy of this licence, visit http://creativecommons.org/licenses/by/4.0/.

\section{References}

1. Q. Tao et al., Adsorption of humic acid to aminopropyl functionalized SBA-15. Microporous Mesoporous Mater. 131(1-3), 177-185 (2010)

2. V. Oskoei et al., Removal of humic acid from aqueous solution using UV/ZnO nano-photocatalysis and adsorption. J. Mol. Liq. 213, 374-380 (2016)

3. H. Harfouchi, D. Hank, A. Hellal, Response surface methodology for the elimination of humic substances from water by coagulation using powdered Saddled Seabream scale as coagulant-aid. Process Saf. Environ. Prot. 99, 216-226 (2016)

4. Y. Wu et al., Removal of humic substances from landfill leachate by Fenton oxidation and coagulation. Process Saf. Environ. Prot. 88(4), 276-284 (2010)

5. F.A. Al Momani, N. Jarrah, Treatment and kinetic study of cyanobacterial toxin by ozone. Journal of Environmental Science and Health Part A 45(6), 719-731 (2010)

6. Z. Noorimotlagh et al., Optimization and genetic programming modeling of humic acid adsorption onto prepared activated carbon and modified by multi-wall carbon nanotubes. Polyhedron 179, 114354 (2020)

7. M. Kersten et al., Surface complexation modeling of arsenate adsorption by akagenéite ( $\beta$-FeOOH)-dominant granular ferric hydroxide. Colloids Surf. A Physicochem. Eng. Asp. 448, 73-80 (2014)

8. S. Zghal et al., One-step synthesis of highly porous carbon graphite/ carbon nanotubes composite by in-situ growth of carbon nanotubes for the removal of humic acid and copper (II) from wastewater. Diam. Relat. Mater. 101, 107557 (2020)

9. J.A. Leenheer, in Chemistry of dissolved organic matter in rivers, lakes and reservoirs. In Environmental Chemistry of Lakes and Reservoirs, ed. by L. A. Baker, vol 237 (Advances in chemistry series, American Chemical Society, Washington, 1994), pp. 195222

10. M. Milinković et al., Biopotential of compost and compost products derived from horticultural waste - effect on plant growth and plant pathogens' suppression. Process Saf. Environ. Prot. 121, 299-306 (2019)

11. F.A. Almomani, R. Delatolla, B. Örmeci, Field study of moving bed biofilm reactor technology for post-treatment of wastewater lagoon effluent at $1^{\circ} \mathrm{C}$. Environ. Technol. 35(13), 1596-1604 (2014)
12. C.S. André, M. Khraisheh, Removal of humic substances from drinking water using GAC and iron-coated adsorbents: consideration of two kinetic models and the influence of mixing. Environ. Eng. Sci. 26, 235-244 (2009)

13. J. Hur, M.A. Schlautman, Molecular weight fractionation of humic substances by adsorption onto minerals. J. Colloid Interface Sci. 264(2), 313-321 (2003)

14. Y.-Q. Hu et al., Effect of pure oxygen aeration on extracellular polymeric substances (EPS) of activated sludge treating saline wastewater. Process Saf. Environ. Prot. 123, 344-350 (2019)

15. G. Hasani et al., A comparative optimization and performance analysis of four different electrocoagulation-flotation processes for humic acid removal from aqueous solutions. Process Saf. Environ. Prot. 121, 103-117 (2019)

16. J. Lladó et al., Removal of pharmaceutical industry pollutants by coal-based activated carbons. Process Saf. Environ. Prot. 104, 294 303 (2016)

17. D.M. McKnight et al., Sorption of dissolved organic carbon by hydrous aluminium and iron oxides occurring at the confluence of Deer Creek with the Snake River, Summit Country. Colorado. Environmental Science \& Technology 26, 1388-1396 (1992)

18. E.S. Melin, H. Ødegaard, Biofiltration of ozonated humic water in expanded clay aggregate filters. Water Sci. Technol. 40(9), 165-172 (1999)

19. K.C. Ho, Y.H. Teow, A.W. Mohammad, Optimization of nanocomposite conductive membrane formulation and operating parameters for electrically-enhanced palm oil mill effluent filtration using response surface methodology. Process Saf. Environ. Prot. (2019)

20. F. Al Momani et al., Combining photo-Fenton process with biological sequencing batch reactor for 2, 4-dichlorophenol degradation. Water Sci. Technol. 49(4), 293-298 (2004)

21. M.G. El-Din et al., Oxidation of resin and fatty acids by ozone: kinetics and toxicity study. Water Res. 40(2), 392-400 (2006)

22. A.B. Albadarin et al., Preliminary investigation of mixed adsorbents for the removal of copper and methylene blue from aqueous solutions. Chem. Eng. J. 255, 525-534 (2014)

23. B. Kakavandi et al., Development of response surface methodology for optimization of phenol and p-chlorophenol adsorption on magnetic recoverable carbon. Microporous Mesoporous Mater. 231, 192-206 (2016)

24. M.A. Al-Anber et al., The performance of defatted jojoba seeds for the removal of toxic high concentration of the aqueous ferric ion. Desalin. Water Treat. 52(1-3), 293-304 (2014)

25. S.I. Siddiqui, S.A. Chaudhry, Iron oxide and its modified forms as an adsorbent for arsenic removal: a comprehensive recent advancement. Process Saf. Environ. Prot. 111, 592-626 (2017)

26. M. Streat, D.J. Horner, Adsorption of highly soluble herbicides from water using activated carbon and hypercrosslinked polymers. Process Saf. Environ. Prot. 78(5), 363-382 (2000)

27. S.D. Faust, O.M. Aly, Adsorption processes for water treatment (Butterworth-Heinemann, Elsevier eBook, 1987)

28. S. Basu, G. Ghosh, S. Saha, Adsorption characteristics of phosphoric acid induced activation of bio-carbon: equilibrium, kinetics, thermodynamics and batch adsorber design. Process Saf. Environ. Prot. 117, 125-142 (2018)

29. R. Radhika et al., Adsorption performance of packed bed column for the removal of perchlorate using modified activated carbon. Process Saf. Environ. Prot. 117, 350-362 (2018)

30. Montgomery, J.M., Water treatment principles and design. Montgomery Consulting Engineers, Inc. John Wiley \& Sons, Inc, 1985

31. U. Khan, R.A.K. Rao, A high activity adsorbent of chemically modified Cucurbita moschata (a novel adsorbent) for the removal of $\mathrm{Cu}$ (II) and $\mathrm{Ni}$ (II) from aqueous solution: synthesis, characterization and metal removal efficiency. Process Saf. Environ. Prot. 107, 238-258 (2017) 
32. Q. Tang, C. Shi, W. Shi, X. Huang, Y. Ye, W. Jiang, J. Kang, D. Liu, Y. Ren, D. Li, Preferable phosphate removal by nano-La(III) hydroxides modified mesoporous rice husk biochars: role of the host pore structure and point of zero charge. Sci. Total Environ. 662, 511-520 (2019)

33. Y. Xu et al., Precipitation of calcium sulfate dihydrate in the presence of fulvic acid and magnesium ion. Chem. Eng. J. 361, 10781088 (2019)

34. M. Khraisheh, M.A. Al-Ghouti, C.A. Stanford, The application of iron coated activated alumina, ferric oxihydroxide and granular activated carbon in removing humic substances from water and wastewater: column studies. Chem. Eng. J. 161(1-2), 114-121 (2010)

35. J. Xie et al., $\mathrm{pH}$ modeling for maximum dissolved organic matter removal by enhanced coagulation. J. Environ. Sci. 24(2), 276-283 (2012)

36. B.P. Allpike et al., A new organic carbon detector for size exclusion chromatography. J. Chromatogr. A 1157(1), 472-476 (2007)

37. Q. Wang et al., Selection of magnetic anion exchange resins for the removal of dissolved organic and inorganic matters. J. Environ. Sci. 24(11), 1891-1899 (2012)

38. M. Al-Ghouti et al., The removal of dyes from textile wastewater: a study of the physical characteristics and adsorption mechanisms of diatomaceous earth. J. Environ. Manag. 69(3), 229-238 (2003)

39. M.A. Al-Ghouti et al., Adsorption mechanisms of removing heavy metals and dyes from aqueous solution using date pits solid adsorbent. J. Hazard. Mater. 176(1-3), 510-520 (2010)

40. H. Freundlich, Over the adsorption in solution. J. Phys. Chem. 57(385471), 1100-1107 (1906)

41. I. Langmuir, The constitution and fundamental properties of solids and liquids. Part I. Solids. J. Am. Chem. Soc. 38(11), 2221-2295 (1916)

42. O. Altın, H.Ö. Özbelge, T. Doğu, Use of general purpose adsorption isotherms for heavy metal-clay mineral interactions. J. Colloid Interface Sci. 198(1), 130-140 (1998)

43. S. Li et al., Adsorption of humic acid from aqueous solution by magnetic $\mathrm{Zn} / \mathrm{Al}$ calcined layered double hydroxides. Appl. Clay Sci., 105414 (2020)
44. S. Liu et al., The promoted dissolution of copper oxide nanoparticles by dissolved humic acid: copper complexation over particle dispersion. Chemosphere 245, 125612 (2020)

45. P.T. Ngueagni et al., Adsorption of $\mathrm{Cu}(\mathrm{II})$ ions by modified horn core: effect of temperature on adsorbent preparation and extended application in river water. J. Mol. Liq. 298, 112023 (2020)

46. M. Ahmedna, W.E. Marshall, R.M. Rao, Surface properties of granular activated carbons from agricultural by-products and their effects on raw sugar decolorization. Bioresour. Technol. 71(2), 103$112(2000)$

47. S. Ram, Infrared spectral study of molecular vibrations in amorphous, nanocrystallyne and $\mathrm{AlO}(\mathrm{OH}), \alpha \mathrm{H} 2 \mathrm{O}$ bulk crystals. Infrared Physics and Technology 42, 547-560 (2001)

48. G. Socrates, Infrared and Raman characteristic group frequencies: tables and charts, . 3rd edn. Chichester, 2000

49. G. Sposito, The environmental chemistry of aluminium. 2nd edn CRC Press, Doan P.T. Characterization of $\mathrm{Cu}-\mathrm{Co}-\mathrm{Cr}-\mathrm{K}$ catalysis. MSc thesis, Faculty of Mississipi State University, USA, 2001

50. Y.H. Li, C.W. Lee, B.K. Gullett, The effect of activated carbon surface moisture on low temperature mercury adsorption. Carbon 40(1), 65-72 (2002)

51. J.K. Bailey, C.J. Brinker, M.L. Mecartney, Growth mechanisms of iron oxide particles of differing morphologies from the forced hydrolysis of ferric chloride solutions. J. Colloid Interface Sci. 157(1), 1-13 (1993)

52. R.L. Cook, C.H. Langford, Structural characterization of a fulvic acid and a humic acid using solid-state ramp-CP-MAS 13C nuclear magnetic resonance. Environmental Science \& Technology 32(5), 719-725 (1998)

53. A.W.P. Vermeer, W.H. van Riemsdijk, L.K. Koopal, Adsorption of humic acid to mineral particles. 1. specific and electrostatic interactions. Langmuir 14(10), 2810-2819 (1998)

54. W.J. Thomas, B. Crittenden, Adsorption technology and design (Butterworth-Heinemann, 1998)

55. I.P. Teermann, M.R. Jekel, Adsorption of humic substances onto B$\mathrm{FeOOH}$ and its chemical regeneration. Water Sci. Technol. 40(9), 199-206 (1999) 